\title{
Effect of Glass Substrates on the Formation of Gold-Silver Colloids in Nanocomposite Thin Films
}

\author{
GANESH SUYAL ${ }^{* \dagger}$, MARTIN MENNIG AND HELMUT SCHMIDT \\ Institut für Neue Materialien, Im Stadtwald, Geb.-43, D-66123 Saarbrücken, Germany \\ ganesh.suyal@epfl.ch
}

Received January 8, 2003; Accepted September 3, 2003

\begin{abstract}
A sol-gel route to synthesize nanocomposite thin films containing phase separated metal colloids of gold $(\mathrm{Au})$ and silver $(\mathrm{Ag})$ was developed. $\mathrm{Ag}-\mathrm{Au}$ colloids were prepared in silica films using dip coating technique. The annealing of the samples in air results in the formation of phase separated $\mathrm{Ag}$ and $\mathrm{Au}$ colloids in $\mathrm{SiO}_{2}$ thin films, showing the surface plasmon peaks at $410 \mathrm{~nm}$ and $528 \mathrm{~nm}$. For the synthesis of phase separated $\mathrm{Ag}$ and $\mathrm{Au}$ colloids on float glass substrates, formation of the silver colloids was found strongly dependent on the surface of the float glass. On the tin rich surface formation of both gold and silver colloids took place, whereas, on the tin poor surface the formation of only gold colloids was observed. The surface dependence of the formation of silver colloids was attributed to the presence of tin as $\mathrm{Sn}^{2+}$ state on the glass surface, which oxidizes into $\mathrm{Sn}^{4+}$ during heat treatment, reducing $\mathrm{Ag}^{+}$into silver colloids.
\end{abstract}

Keywords: phase separated colloids, nanocomposite films, sol-gel, optical properties

\section{Introduction}

Coloration of glasses by metal or non-metal ions was known to mankind some thousand of years ago in Egypt [1]. In this method of coloring, each batch of glass has to be melted separately and the colors produced are generally diffuse and dull. Another rather modern alternative for the production of colored glasses is to coat them with a film containing nanosized metal colloids (i.e. $\mathrm{Ag}, \mathrm{Au}, \mathrm{Cu}$ and $\mathrm{Pd}$ ) [2]. This method allows the generation of very intense colors due to the surface plasmon resonance, by a film as thin as $100 \mathrm{~nm}$. Furthermore, this method does not necessitate melting a separate batch for each color. Besides their application as colored coatings, metal colloids dispersed in glass matrix have drawn great interest recently, due to their enhanced third-order nonlinear susceptibility $\chi^{(3)}[3-5]$.

\footnotetext{
*To whom all correspondence should be addressed.

${ }^{\dagger}$ Present address: Federal Institute of Technology, EPFL, IMX-LC, Ecublens, CH-1015 Lausanne, Swizerland.
}

Sol-gel is a relatively new method to fabricate thin films on different type of substrates. This method has been employed to synthesize monometallic colloidal particles of $\mathrm{Ag}$ and $\mathrm{Au}$ in $\mathrm{TiO}_{2}[6]$ and $\mathrm{Pd}$ [7], $\mathrm{Cu}$ [8], $\mathrm{Ag}$ [9] and $\mathrm{Au}$ [10] colloids in $\mathrm{SiO}_{2}$ and $\mathrm{PbO}-\mathrm{SiO}_{2}$ coatings [11]. Several other methods like chemical reduction $[12,13]$ or UV photo reduction $[14,15]$ of the mixed solution of two metal salts, have been used for the preparation of bimetallic colloidal particles in solution. However, only a few attempts have been made towards the synthesis of such bimetallic colloidal particles in thin film form. It is challenging and of scientific interest to synthesize nanocomposite thin films containing two different metallic species and to investigate their optical properties. The present work is therefore, aimed to fabricate thin films containing phase separated colloids of silver and gold on float glass substrates and to study the effect of the tin, present on the surface of substrates on the formation of phase separated Ag and Au colloids.

It is known from the literature that by dissolving gold/silver salts in a TEOS sol, thin films containing 
gold/silver colloids can be formed by the thermal reduction of their ions. But the thickness of the $\mathrm{SiO}_{2}$ films obtained by this route is very small $(<100 \mathrm{~nm})$ which also results in a very small optical density. Spanhel et al. [16] showed that by means of functionalized silanes gold ions can be incorporated in organic-inorganic coatings and can be reduced thermally to gold colloids. Using the same concept Schmitt [17] has made systematic studies of thin films containing noble metal colloids synthesized by the sol-gel route. He has obtained interesting colors i.e. ruby from gold, yellow from silver and ruby to green from copper colloids in hybrid coatings (thickness up to $1 \mu \mathrm{m}$ ).

In order to achieve the mixed colors of yellow and ruby, thin films containing a mixture of phase separated colloids of gold and silver were synthesized. A great problem however, in the synthesis of the thin films containing a mixture of $\mathrm{Au}$ and $\mathrm{Ag}$ is that $\mathrm{Ag}^{+}$ions readily react with halogen ions to form water insoluble silver halides. To overcome this problem, gold and silver ions both were stabilized with a complexing agent $N$-(2-Aminoethyl-3-aminopropyl) trimethoxy silane (DIAMO), before mixing.

\section{Experimental}

For the synthesis of thin films, matrix sol was synthesized from 3-glycidoxypropyl trimethoxysilane (GPTS) and tetraethoxysilane (TEOS). To synthesize GPTS-TEOS sol with a molar ratio of $4: 1$, a mixture of $120 \mathrm{ml}$ ethanol, $160 \mathrm{ml}$ GPTS and $40 \mathrm{ml}$ TEOS was taken in a flask connected with a water condenser and heating arrangement. After heating at $80^{\circ} \mathrm{C}$ for $0.5 \mathrm{~h}$, $28.5 \mathrm{ml}$ of 0.1 molar $\mathrm{HNO}_{3}$ solution was added dropwise to it within 3-4 min. This mixture was further reacted for $24 \mathrm{~h}$ under the same conditions and finally $120 \mathrm{ml}$ more ethanol was added to it followed by further stirring for $0.5 \mathrm{~h}$ at $80^{\circ} \mathrm{C}$. The resulting sol was cooled to room temperature to get a stable GPTS-TEOS sol.

To synthesize thin films containing Ag and Au colloids with a molar ratio of 1:1 for example, $0.174 \mathrm{~g}$ of hydrogen tetrachloroaurate $\left(\mathrm{HAuCl}_{4} \cdot 3 \mathrm{H}_{2} \mathrm{O}\right)$ was dissolved in $5.6 \mathrm{ml}$ ethanol and $0.340 \mathrm{ml}$ of DIAMO (Au:DIAMO = 1:3) was added to it dropwise. After 15 min of stirring $4.8 \mathrm{ml}$ of GPTS-TEOS sol was added to it. In another glass container, a silver containing sol was synthesized in parallel by dissolving $0.086 \mathrm{~g}$ of $\mathrm{AgNO}_{3}$ in $4.0 \mathrm{ml}$ methanol, to which $0.113 \mathrm{ml}$ of DIAMO (Ag:DIAMO = 1:1) was added. After 15 min of stirring $6.8 \mathrm{ml}$ of GPTS-TEOS sol was added to it.
Both silver and gold containing sols were further stirred for $4 \mathrm{~h}$ at $25^{\circ} \mathrm{C}$, followed by the addition of the silver containing sol to the gold containing sol. For all the molar proportions total concentration of $\mathrm{Ag}+\mathrm{Au}$ was kept constant to $1.02 \times 10^{-3} \mathrm{~mol}$.

Samples were prepared using a dip coating technique. The glass substrates were coated with a lifting speed of $4 \mathrm{~mm} / \mathrm{s}$ and dried at $80^{\circ} \mathrm{C}$ in an oven for $30 \mathrm{~min}$. These dried samples were heat-treated in air at temperatures between $150^{\circ} \mathrm{C}$ and $550^{\circ} \mathrm{C}$ with a heating rate of $100 \mathrm{~K} / \mathrm{h}$.

To investigate the optical properties, UV-Vis absorption spectra of the films were recorded with an OMEGA $30 \mathrm{UV}$-Vis spectrometer (Bruins Instrument) between 300 and $1000 \mathrm{~nm}$. The thickness of the films were measured with a profilometer (diamond stylus, nanosurf). To obtain information about the crystallinity and to estimate the crystallite size, X-ray diffraction measurements were conducted on a siemens automated diffractometer working at $40 \mathrm{KV}$ and $35 \mathrm{~mA}$ with a $\mathrm{LiF}$ monochromator and the radiation used was $\mathrm{CuK} \alpha$ $(1.5405 \AA)$. The diffracted X-rays were collected by scanning between $2 \theta=20-60^{\circ}$ in $0.04^{\circ}$ steps. To perform the electron microscopic characterization of the phase separated colloidal particles of Ag and Au, JEOL $200 \mathrm{CX}$ high-resolution transmission electron microscope (HR-TEM) was used. Float glasses with dimensions of $7.5 \mathrm{~cm} \times 2.5 \mathrm{~cm} \times 0.2 \mathrm{~cm}$ were used as substrates for the fabrication of thin films in the present study.

\section{Results and Discussion}

All the films appeared very transparent after annealing at different temperatures. The color of the films was a mixture of yellow and ruby. The thickness of the films were measured to be equal to $500 \mathrm{~nm}$ for the samples heated at $250^{\circ} \mathrm{C}$, it decreases to $360 \mathrm{~nm}$ at $350^{\circ} \mathrm{C}$ and $225 \mathrm{~nm}$ at $450^{\circ} \mathrm{C}$, a film thickness of $175 \mathrm{~nm}$ was measured after the thermal treatment at $550^{\circ} \mathrm{C}$.

\subsection{UV-Vis Spectroscopic Studies}

In order to study the optical properties of the samples, their optical absorption spectra were recorded. The UVVis spectra of $\mathrm{SiO}_{2}$ thin films containing phase separated $\mathrm{Ag}$ and $\mathrm{Au}$ colloids $(\mathrm{Ag}: \mathrm{Au}=1: 2)$ and densified at different temperatures are shown in Fig. 1. 


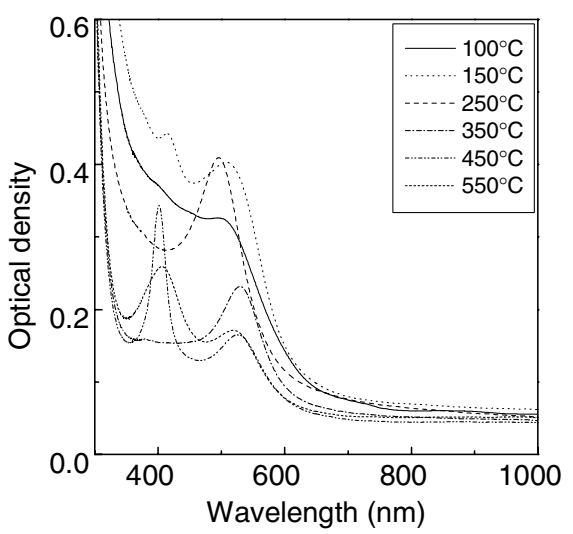

Figure 1. UV-Vis absorption spectra of $\mathrm{SiO}_{2}$ thin films containing phase separated colloids of $\mathrm{Ag}$ and $\mathrm{Au}(\mathrm{Ag}: \mathrm{Au}=1: 2)$ as a function of densification temperature.

This figure shows that for the samples heated at $100^{\circ} \mathrm{C}$ only one absorption peak was observed. Whereas, heating the sample at $150^{\circ} \mathrm{C}$ generates two plasmon peaks at $413 \mathrm{~nm}$ and $510 \mathrm{~nm}$. For the sample heated at $250^{\circ} \mathrm{C}$ only one peak with the peak maximum at $493 \mathrm{~nm}$ was observed. Heating of the samples at $450^{\circ} \mathrm{C}$ generates two absorption peaks at 527 $\mathrm{nm}$ and $400 \mathrm{~nm}$, corresponding to the plasmon absorption of colloidal gold and silver respectively. Whereas, heating at $550^{\circ} \mathrm{C}$ decreases the intensity of absorption peaks.

It has been shown elsewhere [18], that for $\mathrm{Ag}-\mathrm{Au}$ alloy colloids only one absorption peak is observed, which is centered between pure gold and pure silver plasmon peaks and gradually shifts towards colloidal gold absorption on increasing the molar fraction of gold. The appearance of only one peak at $493 \mathrm{~nm}$ for the samples heated at $250^{\circ} \mathrm{C}$ is most likely due to the formation of bimetallic colloids of $\mathrm{Ag}$ and $\mathrm{Au}$.

Figure 1 shows an unusual behavior of the absorption spectrum for the thin films densified at $250^{\circ} \mathrm{C}$. Therefore, the UV-Vis absorption spectra of the thin films densified at $250^{\circ} \mathrm{C}$ were recorded as a function of their molar ratio and are illustrated in Fig. 2.

This figure shows that the absorption peak positions do not depend much on the molar concentration of $\mathrm{Ag}$ and $\mathrm{Au}$. For the films with Ag:Au molar ratio of 4:1 the peak is positioned at $473 \mathrm{~nm}$, shifting to $483 \mathrm{~nm}$ for the molar ratio of 2:1 and finally to $491 \mathrm{~nm}$ for the molar ratio of 1:2. This observed shift of the peak position with respect to the change in gold and silver molar ratio is not in agreement to the calculated peak shift for the alloy colloids [19].

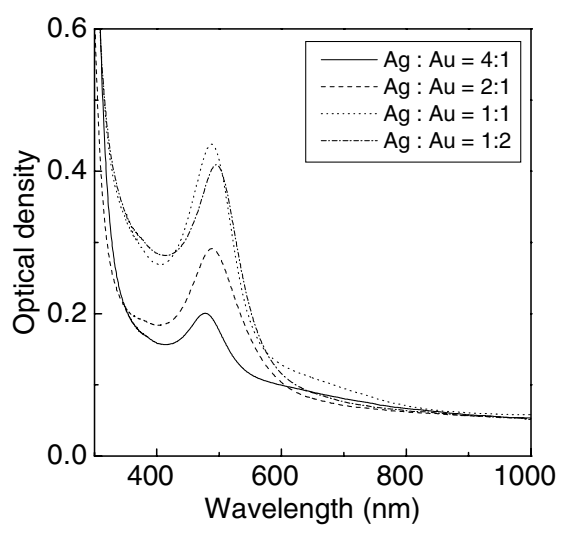

Figure 2. UV-Vis spectra of thin films containing a mixture of Ag and $\mathrm{Au}$ colloids densified at $250^{\circ} \mathrm{C}$ in air, for different molar ratios of $\mathrm{Ag}$ and $\mathrm{Au}$.

During the synthesis of bimetallic particles of $\mathrm{Ag}$ and $\mathrm{Au}$, Ehler et al. [20] have observed that the energy of the resonance absorption peak is nearly independent to the alloy composition. They attributed this unusual behavior to the formation of alloy colloids at the interface between the two metals and concluded that the optical properties of the $\mathrm{Ag}-\mathrm{Au}$ alloy formed at the interface of the two metals will certainly be different than those of either of the pure metal films. Therefore, on the basis of the observed absorption spectra in the present work, it can be said that for the samples heated at $250^{\circ} \mathrm{C}$ the formation of some bimetallic particles is taking place. Further research has to be conducted in order to understand this unusual behavior.

Another possibility may be the formation of colloidal particles, which are composed of the separate gold and silver particles. It has been shown by Toe et al. [21] that as the penetration depth in UV-Vis spectroscopy is much greater than the size of the particles, if the separate metallic components are either on the surface or inside the particles, there should be two distinct absorption peaks. Our observation of a single peak thus discards the above assumption.

In order to confirm if the colloidal particles formed at $250^{\circ} \mathrm{C}$ are bimetallic particles or phase separated particles of Ag and Au, TEM investigations were carried out. HR-TEM micrograph of thin film containing bimetallic particles of $\mathrm{Ag}-\mathrm{Au}$ (molar ratio of $\mathrm{Ag}$ : $\mathrm{Au}=1: 2$, heated at $250^{\circ} \mathrm{C}$ ) is shown in Fig. 3.

The TEM results showed that the colloidal particles with diameter ranging from 5 to $30 \mathrm{~nm}$ were formed [18]. The high-resolution micrograph of a single particle of $\approx 13 \mathrm{~nm}$ diameter is shown in Fig. 3 (inset). 


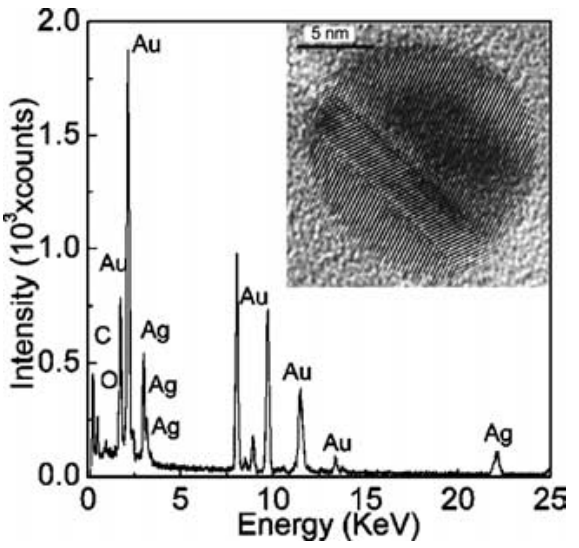

Figure 3. HR-TEM micrograph of a single colloidal particle and its EDX spectra $\left(\mathrm{Ag}: \mathrm{Au}=1: 2\right.$, heat treated at $250^{\circ} \mathrm{C}$ in air for $\left.1 \mathrm{~h}\right)$.

In order to determine the composition of the formed colloidal particles, EDX analysis of some of the particles and glass matrix was carried out. EDX profiles of a particle, shown in Fig. 3, reveal that the particle is composed of 67.2 atom\% of gold and 32.8 atom $\%$ of silver. Presence of $\mathrm{Cu}$ peaks in EDX profiles is due to the copper grid used for the sample preparation. EDX analyses of matrix show the absence of gold and silver both and the presence of Si, C and O only. EDX analyses of a single particle confirm the bimetallic nature of the particles composed of $\mathrm{Ag}$ and $\mathrm{Au}$ both.

The absorption spectra of the films containing a mixture of $\mathrm{Ag}$ and $\mathrm{Au}$ colloids and heat-treated at $450^{\circ} \mathrm{C}$ are shown in Fig. 4, as a function of their molar ratio.

This figure shows that two peaks positioned at $\approx 400 \mathrm{~nm}$ and $\approx 520 \mathrm{~nm}$ (corresponding to silver and

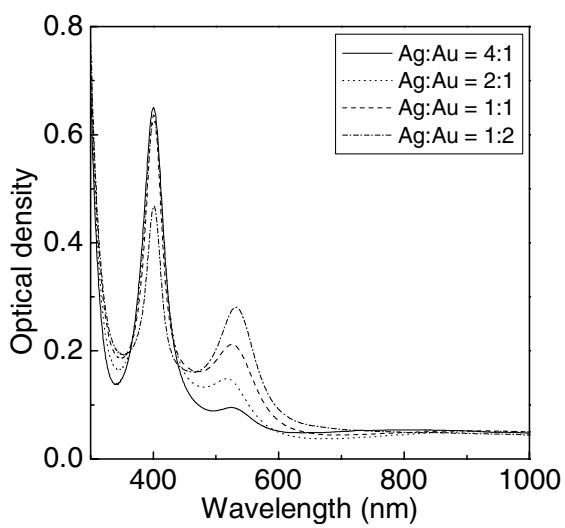

Figure 4. UV-Vis absorption spectra of $\mathrm{SiO}_{2}$ thin films containing $\mathrm{Ag}$ and $\mathrm{Au}$ colloids as a function of their molar ratio (samples were heat treated at $450^{\circ} \mathrm{C}$ ). gold plasmon peak respectively) were observed for all the molar ratios. These observations indicate the formation of both gold and silver colloids in the thin films. However, a small shift towards the lower wavelength of absorption peak of gold was observed with decreasing molar percentage of gold, this shift may be due to the formation of smaller colloidal particles on decreasing the molar percentage.

\subsection{Calculation of Theoretical Absorption Spectra of Phase Separated Ag and Au Colloids}

Absorption spectra of thin films containing $\mathrm{Ag}-\mathrm{Au}$ colloids were calculated using the concept that the different types of the particles are phase separated in a glass matrix. Therefore, all of them then will show their independent plasmon peaks. The resulting spectrum will be the physical addition of the UV-Vis spectrum of the corresponding metal colloids, in which the intensity of the respective plasmon peaks will be proportional to the mixed ratios. Figure 5 shows the calculated extinction spectra for the phase separated colloids having different molar ratios. Absorption spectra for pure gold and pure silver colloids were calculated using Mie theory [22], for the colloidal volume concentration of $10^{-6}$ and the refractive index of 1.46 .

Theoretical spectra show two absorption peaks corresponding to $\mathrm{Ag}$ and $\mathrm{Au}$ plasmon frequencies. The peak intensities are directly proportional to the gold and silver molar ratio. Comparing the observed and theoretical spectra, it can be said that the appearance of two peaks in the present study is due to the formation of a mixture of $\mathrm{Ag}$ and $\mathrm{Au}$ colloids in thin films.

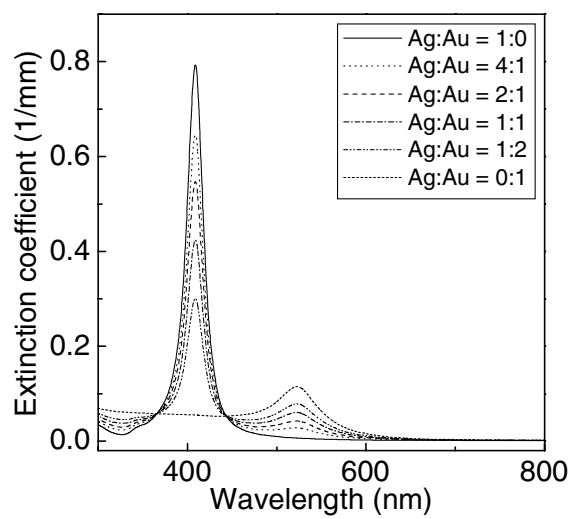

Figure 5. Theoretical absorption spectra of phase separated colloids of $\mathrm{Ag}$ and $\mathrm{Au}$, calculated after Mie-theory (refractive index of the medium is 1.46 and particle radius is $10 \mathrm{~nm}$ ). 


\subsection{Effect of the Tin Content of Float Glass on the Formation of $\mathrm{Ag}-\mathrm{Au}$ Colloids}

During the synthesis of the gold and silver colloids on the float glasses, it was observed that the formation of colloids is strongly dependent to the surface of the glass substrate. The absorption spectra of thin films containing $\mathrm{Ag}$ and $\mathrm{Au}$ colloids ( $\mathrm{Ag}: \mathrm{Au}=2: 1$, densification at $450^{\circ} \mathrm{C}$ ) coated on different surfaces of the glass substrates are shown in Fig. 6.

This figure shows that for the thin films coated on one surface of glass, only one absorption peak at $525 \mathrm{~nm}$ was observed, which is due to the colloidal gold. Whereas, the thin films on the other surface of the glass show two absorption peaks at $410 \mathrm{~nm}$ and $525 \mathrm{~nm}$, corresponding to colloidal silver and gold respectively. It is known that the formation of colloidal silver in the near surface region of float glass is related to the concentration and chemical state of the tin in the glass surface. Earlier studies [23, 24] have shown that the concentration of the tin at the surface of the tin-rich face of float glass is very high (as much as $30 \mathrm{wt} \%$ ) and decreases rapidly in the first $10 \mathrm{~nm}$ of the glass. The tin concentration in the other face of the float glass is very low. Both Seiger [25] and Ernsberger [26] have reported that a large portion of the tin is in the stannous state. Since stannous tin is known to react with ionic silver via the reaction

$$
\mathrm{Sn}^{2+}+2 \mathrm{Ag}^{+}=\mathrm{Sn}^{4+}+2 \mathrm{Ag}^{0}
$$

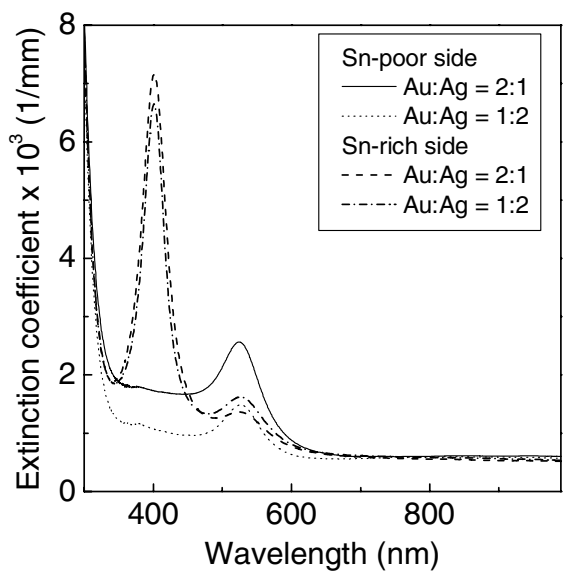

Figure 6. Surface dependence of the formation of $\mathrm{Ag}$ and $\mathrm{Au}$ colloids on float glass substrates, samples were heat treated at $450^{\circ} \mathrm{C}$ in air.
Table 1. Colloidal turnover of silver and gold particles formed on the tin rich and tin poor surface of the float glass, the samples were densified at $450^{\circ} \mathrm{C}$ in air.

\begin{tabular}{lcccc}
\hline & \multicolumn{2}{c}{ Sn rich } & & Sn poor \\
\cline { 2 - 3 } $\mathrm{Ag}: \mathrm{Au}$ & $\mathrm{Ag}(\%)$ & $\mathrm{Au}(\%)$ & & $\mathrm{Au} \mathrm{( \% )}$ \\
\hline $4: 1$ & 65 & 65 & 65 \\
$2: 1$ & 74 & 52 & 63 \\
$1: 1$ & 81 & 51 & 65 \\
$1: 2$ & 100 & 68 & 68 \\
\hline
\end{tabular}

Ernsberger [26] suggested that the stannous tin in the near surface region of float glass could react with the silver ions to produce silver colloids.

It can also be seen from Fig. 6 that the extinction coefficients corresponding to Ag plasmon peak are almost same for the molar ratios of $\mathrm{Ag}: \mathrm{Au}=1: 2$ and $2: 1$. In other words, the formation of silver colloids is independent to the original silver concentration. It clearly indicates that the formation of silver colloids is dependent to the tin content of the glass surface. In order to evaluate the amount of colloidal particles, colloidal turnover for the gold and silver on the tinrich and tin-poor surfaces of the float glass was calculated. The colloidal turnover is the measure of metallic particles in percentage; those have been converted from metal ions to colloids [17]. To evaluate the colloidal turnover, the UV-Vis extinction spectra were deconvoluted and the corresponding spectrum for gold and silver colloids was used for the calculation [18]. The calculated turnovers for gold and silver colloids are shown in Table 1.

This table clearly shows that the colloidal turnover for gold is almost same for the tin poor side. For the tin rich side on the other hand, the colloidal turnover for gold is varying from 52 to $65 \%$, however, a gradual decrease in the colloidal turnover of silver was observed with the increasing molar fraction of silver. Which is $100 \%$ for the molar ratio of $\mathrm{Ag}: \mathrm{Au}=1: 2$, decreases to $80 \%$ for $\mathrm{Ag}: \mathrm{Au}=1: 1$ and finally to $65 \%$ for the $\mathrm{Ag}: \mathrm{Au}=4: 1$. These observations also indicate that the formation of silver colloids is directly dependent to the tin content of the float glass.

\subsection{Effect of Pre-Treatment of Glass Substrates on the Formation of Phase Separated Ag and Au Colloids}

In order to verify if the surface dependence of the colloid formation is due to the presence of tin only, a 


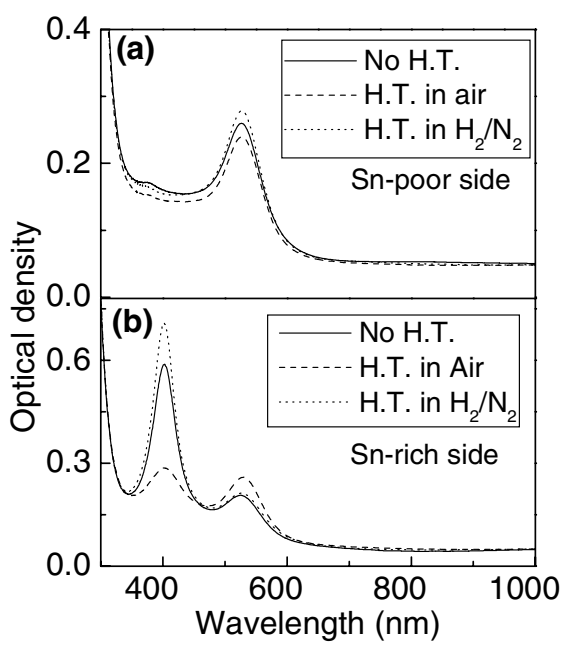

Figure 7. UV-Vis absorption spectra of films containing Ag and Au colloids, fabricated on: (a) tin poor surface and (b) tin rich surface. Float glass substrates were pre-treated under different atmospheres before dip coating.

number of float glass substrates were heated at $500^{\circ} \mathrm{C}$ for $18 \mathrm{~h}$ either in $\mathrm{H}_{2}$ or in air with the heating rate of $100 \mathrm{~K} / \mathrm{h}$. After cooling to room temperature, thin films were fabricated on these glass substrates and heattreated at $500^{\circ} \mathrm{C}$ in air for $1 \mathrm{~h}$. The UV-Vis spectra of the samples prepared on different surfaces of the glass substrates are shown in Fig. 7.

Figure 7(a) shows that for the tin poor surface only one absorption peak due to gold colloids is observed. For the samples pre-treated in air the observed optical density corresponding to Au colloids is slightly lower than the samples that are not pre-treated. Whereas, for the samples pre-treated in reducing atmosphere $\left(\mathrm{H}_{2}\right)$ the observed optical density is slightly higher. This is because the gold is known to be reduced very fast even without any reducing agent [2]. Therefore, the formation of gold colloids is less dependent to the presence of tin.

The UV-Vis spectra of the tin rich surface (Fig. 7(b)) show that for the sample without any pre-treatment two peaks at $410 \mathrm{~nm}$ and $528 \mathrm{~nm}$ were observed. The optical density of the peak at $410 \mathrm{~nm}$ decreases remarkably on pre-heating the samples in air, whereas, it increases on pre heating the samples under reducing atmosphere $\left(\mathrm{N}_{2} / \mathrm{H}_{2}=92 / 8\right)$. It means that the hydrogen pre-treatment increased the silver colloid formation, while the air pre-treatment decreased the silver colloid formation.

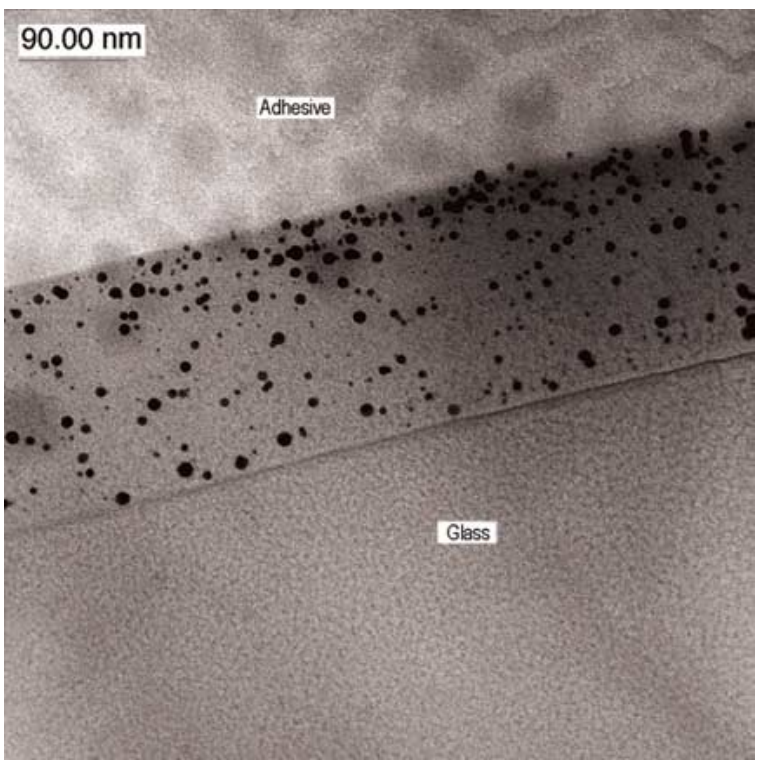

Figure 8. HR-TEM image showing colloidal particle dispersed in glass matrix (samples were densified at $550^{\circ} \mathrm{C}$ in air).

This phenomenon appears to be a function of the effect of pre-treatment on the chemical state of the tin. Pre-treatment in a reducing atmosphere may further reduce the tin in the near surface region, which in turn, means that more silver ions will be reduced during the heat treatment. Pre-treatment in air results the oxidation of tin to the stannic state, so that less stannous tin is available to reduce the silver ions.

\subsection{HR-TEM Characterization}

High resolution transmission electron microscopy (HR-TEM) was performed to see the shape and size of the particles formed. HR-TEM micrograph of thin film containing Ag and Au colloids is shown in Fig. 8. Thin films were coated on the tin poor side of the glass substrates and heat-treated at $550^{\circ} \mathrm{C}$.

This figure shows the TEM bright field image of $\mathrm{SiO}_{2}$ coating containing colloidal particles. Here it can be observed that relatively small particles with a diameter range of 1 to $12 \mathrm{~nm}$ are formed, which are uniformly dispersed in the glass matrix. Fourier filtering of an image showed the formation of polycrystalline nanoparticles.

In order to see the composition of the particles formed, their EDX analysis was carried out. The EDX analysis of a particle and a large region showed the 


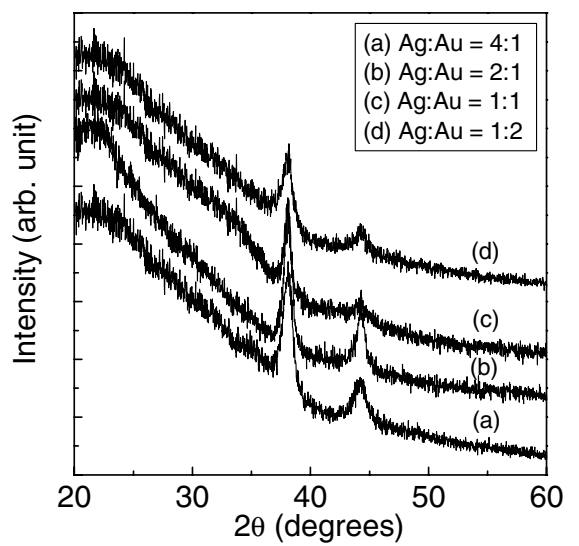

Figure 9. The X-ray diffraction patterns of $\mathrm{SiO}_{2}$ thin films containing $\mathrm{Ag}$ and $\mathrm{Au}$ colloids (all the samples were densified at $550^{\circ} \mathrm{C}$ for $1 \mathrm{~h}$ in air).

peaks corresponding to gold only, indicating that the particle and the large region, both, do not contain any silver for the samples heated at $550^{\circ} \mathrm{C}$. It has been shown elsewhere [18] that the silver on heating in air oxidizes and diffuses into the glass, which is again reduced at higher temperature to form silver colloids. Since the HR-TEM investigations were carried out on thin films only, the absence of the silver particles in the micrographs is well justified.

\subsection{X-ray Diffraction Characterization}

X-ray diffraction patterns of thin films were recorded to see the crystalline behavior of the particles formed and to calculate the size of crystallites using Scherrer equation. The XRD patterns of thin films containing $\mathrm{Ag}-\mathrm{Au}$ colloids are shown in Fig. 9 as a function of their molar ratio.

As the particles are phase separated colloids of gold and silver, their XRD patterns have to be the simple addition of the corresponding XRD patterns of gold and

Table 2. Angle $(2 \theta)$, corrected half width $(\beta)$ corresponding to (111) peak and the crystallite diameter (d) after Scherrer equation, for the phase separated $\mathrm{Ag}$ and Au colloids.

\begin{tabular}{llll}
\hline $\mathrm{Ag}: \mathrm{Au}$ & $2 \theta\left(^{\circ}\right)$ & $\beta\left(^{\circ}\right)$ & 'd' (nm) \\
\hline $4: 1$ & 38.012 & 0.67 & 19.0 \\
$2: 1$ & 38.119 & 0.92 & 13.0 \\
$1: 1$ & 38.069 & 0.70 & 18.0 \\
$1: 2$ & 38.050 & 0.92 & 13.0 \\
\hline
\end{tabular}

silver. As the XRD patterns of gold and silver are almost same, the resulting XRD patterns may have been resulted by the addition of gold and silver XRD patterns. These XRD patterns were used for the calculation of particle size using Scherrer equation. The calculated diameters of the particles (d) are given in Table 2. Particle size calculated as above compares well with the particle size measured using HR-TEM analysis.

\section{Conclusions}

A sol-gel route for the synthesis of nanocomposite thin films containing phase separated colloids of gold and silver has been developed successfully. Structural and chemical analysis of Ag-Au nanoclusters in a silica matrix was performed by means of UV-Vis spectroscopy, HR-TEM and EDX. On comparing these results with our previous studies [19], it can be concluded that UVVis spectroscopy can successfully be applied to differentiate between alloy- and phase separated- colloids of gold and silver. The theoretical absorption spectra for $\mathrm{Ag}-\mathrm{Au}$ colloids were calculated using Mie theory. A good agreement was found between theoretical and measured absorption spectra.

During the synthesis of gold and silver colloids, the formation of silver colloids was found strongly dependent on the surface of the glass substrates. On the tin rich surface, formation of both gold and silver colloids took place, whereas, on the tin poor surface the formation of gold colloids only was observed. This dependence of the formation of silver colloids was attributed to the presence of the tin as $\mathrm{Sn}^{2+}$ state, which oxidizes into $\mathrm{Sn}^{4+}$ during heat treatment reducing the $\mathrm{Ag}^{+}$into silver colloids.

\section{Acknowledgment}

The authors would like to thank Dr. U. Werner for carrying out the TEM investigations and Ministry of Finance, State of Saarland, Saarbrücken (Germany), for financial support.

\section{References}

1. Encyclopedia of Chemical Technology, 3rd edn., vol. 11, p. 807.

2. W.A. Weyl, Colored Glasses (Sheffield Soc. Glass Tech., 1951).

3. R.H. Magruder III, R.F. Haglund, Jr., L. Yang, J.E. Wittig, and R.A. Zuhr, J. Appl. Phys. 76, 708 (1994).

4. P. Mazzoldi, G.W. Arnold, G. Battaglin, F. Gonella, and R.F. Haglund, Jr., J. Nonlinear Opt. Phys. and Materials 5, 285 (1996).

5. E.M. Vogel, J. Am. Ceram. Soc. 72, 719 (1989). 
6. M. Mennig, M. Pietsch, K. Endres, C. Fink-Straube, and H. Schmidt, in Proc. 67th Annual Meeting of the DGG, in Bayreuth, Extended abstract book (oral) 202, 1997.

7. T. Burkhart, M. Mennig, H. Schmidt, and A. Liciulli, Mat. Res. Soc. Symp. Proc. 246, 779 (1994).

8. M. Mennig, M. Schmitt, B. Kutsch, and H. Schmidt, in SPIE Sol-Gel Optics III, edited by J.D. Mackenzie (SPIE, Bellingham, Washington, 1994), vol. 2288, p. 120.

9. M. Mennig, M. Schmitt, and H. Schmidt, J. Sol-Gel Sci. Tech. 8, 1035 (1997)

10. M. Mennig, M. Schmitt, U. Becker, G. Jung, and H. Schmidt, in SPIE Sol-Gel Optics III, edited by J.D. Mackenzie (SPIE, Bellingham, Washington, 1994) vol. 2288, p. 130.

11. M. Mennig, K. Endres, M. Schmitt, and H. Schmidt, J. NonCryst. Solids 218, 373 (1997).

12. Y. Wang and H. Liu, Polym. Bull. 25, 139 (1991).

13. K. Esumi, M. Shiratori, H. Ishizuka, T. Tano, K. Torigoe, and K. Meguro, Langmuir 7, 457 (1991).

14. B.K. Toe, K. Keating, and Y.H. Kao, J. Am. Chem. Soc. 109, 3494 (1987).
15. T. Sato, S. Kuroda, V. Takami, Y. Yonezaba, and H. Hada, Appl. Organo. Chem. 5, 261 (1991).

16. L. Spanhel, M. Mennig, and H. Schmidt, Bol. Soc. Esp. Ceram. Vid. 31-C 7, 268 (1992).

17. M. Schmitt, Ph.D. Thesis, INM, University of Saarland, Germany (1998).

18. G. Suyal, Ph.D. Thesis, INM, University of Saarland, Germany (2002).

19. G. Suyal, M. Mennig, and H. Schmidt, J. of Mat. Sci. 38, 1645 (2003).

20. T.T. Ehler and L.J. Noe, Langmuir 11, 4177 (1995).

21. B.K. Toe, K. Keating, and Y.H. Kao, J. Am. Chem. Soc. 109, 3494 (1987).

22. G. Mie, Ann. Phy. 25, 377 (1908).

23. W.E. Baitinger, P.W. French, and E.L. Swart, J. Non-Cryst. Solids 38, 749 (1980).

24. L. Colombin, H. Charlier, A. Jelli, G. Debras, and J. Verbist, J. Non-Cryst. Solids 38, 551 (1980).

25. J.S. Seiger, J. Non-Cryst. Solids 19, 213 (1975).

26. F.M. Ernsberger, US Patent 4155735 (1979). 